\title{
A New Practical Approach for Discrimination between Inrush Currents and Internal Faults in Power Transformers
}

\author{
Hossein Mohammadpour ${ }^{1} \cdot$ Rahman Dashti $^{1} \cdot$ Hamid Reza Shaker $^{2}$ (I)
}

Received: 21 September 2019 / Accepted: 30 January 2020 / Published online: 10 February 2020

(C) Springer Nature Singapore Pte Ltd. 2020

\begin{abstract}
The power transformers are protected by differential relays. These relays use the second harmonic blocking to distinguish inrush current from internal fault current. In recent years, the performance of the second harmonic blocking has decreased and therefore new methods are needed to distinguish inrush current from internal fault current. The aim of this study is to present a new method for discrimination between magnetizing inrush currents and internal faults in differential protection of power transformers. The proposed scheme is based on calculating the dq0 transformation of current signals in the abc phases of transformer terminals for different inrush current and internal fault signals. Creating new waveforms using mathematical calculations, the signals are identifiable by their characteristics. The accurate diagnosis is based on creating a classification pattern for the discrimination algorithm. To substantiate the preciseness of proposed methodology, different states of inrush and fault currents are simulated in PSCADTM/EMTDCTM. Consequently, calculations and the distinction process are carried-out in MATLAB environment. The discrimination procedure needs only current signal data of less than a quarter of power frequency cycle and uses very simple classification rules. Eventually, both simulation and experimental results show that the accuracy of proposed method is high. The results of this study confirm that simple and accurate methods which use patterns can be developed for distinguishing the internal faulty current of transformer from inrush and healthy current.
\end{abstract}

Keywords Power transformer $\cdot$ Inrush current $\cdot$ Differential protection $\cdot$ Internal fault $\cdot$ Park transformation $\cdot$ Classification

\section{Introduction}

Many power networks are operated in different conditions and with different control devices [1-4]. The differential protection is one of the most appropriate methods of power transformer protection $[5,6]$. Since the currents are too high in the differential protection zone, Current Transformers (CTs) decrease the currents proportionally to become operational in differential relays, and other measurement and recording units. In case of fault occurrence, the differential relay sends

Hamid Reza Shaker

hrsh@mmmi.sdu.dk

Rahman Dashti

r.dashti@pgu.ac.ir

1 The Clinical-Laboratory Center of Power System and Protection, Department of Electrical Engineering, Faculty of Engineering, Persian Gulf University, Bushehr 7516913817, Iran

2 The Center for Energy Informatics, The Maersk Mc-Kinney Moller Institute, University of Southern Denmark, Odense, Denmark a trip signal to the circuit breakers to prevent the continuation of fault current in the system. Nevertheless, due to the characteristics of inrush transient, the differential relay might cause an inaccurate recognition and detect it as a fault occurrence. Among the undesirable factors that need to be taken into consideration in accomplishment of differential protection (such as CT errors, tap change, $\mathrm{CT}$ error increment during the external faults, single-phase earth fault on the HV side, inter-turn short circuit, and magnetizing inrush), solutions to all of them except the magnetizing inrush is relied on the differential protection [5]. IEEE Guide for Protecting Power Transformers [7] defines the magnetizing inrush as: "a phenomenon that causes the violation of the basic principle of differential relaying". In addition, inrush current conditions also occur more than short circuits [8]. For the mentioned reasons, it should be considered to draw a distinction between fault and inrush current signals in order to increase the reliability of the power system.

The differential protection is one of the first protections ever used in power systems, which has been put into practice since the end of nineteenth century [9]. Besides, "the study of 
transformer excitation inrush phenomena has spanned more than 50 years" [10]. To override the inrush current, a time delay or a temporary relay desensitization has been used in the early designs of the differential protection [11]. These techniques increased the operation time and were not dependable in case of fault existence at the moment of transformer energization. Nowadays, the most common used method to identify the magnetic inrush is based on second harmonic restraint [5]. On the other hand, the harmonic restraint-based methods have several drawbacks. Improvements in transformer core materials can reduce the second harmonic of inrush currents [12] in modern transformers. On top of that, the main disadvantage of harmonic restraint methods is that the harmonics of Extra High Voltage (EHV) long-distance transmission lines can cause the relay malfunction [5].

Several techniques have recently been employed to resolve this problem. Different methods based on Discrete Wavelet Transform (DWT) have been proposed to demonstrate a reliable outcome to detect short circuit and magnetizing inrush currents in power transformers [12-18] DWT-based methods are very common and useful for analyzing transients of power systems. Nevertheless, some of them use complex computations and rules in the inrush current recognition algorithm. Furthermore, several DWT-based methods are sensitive to the noise signals. Several other alternative techniques have been proposed to detect a difference in internal fault and inrush currents of power transformers as well. Methods based on DWT and Support Vector Machine (SVM) [19], differential current gradient [20], Decision Tree (DT) [21], JilesAtherton model parameters [22], and Artificial Neural Network (ANN) and Bayesian classifier [23] are some of the examples to be highlighted.

A TLDP (Transmission Line Differential Protection) method based on alpha plane has been presented in [24, 25]. An alpha plane of incremental complex power has been used in [19] and the restraint characteristic is denied. In this TLDP, the synchro voltage and current data are used to calculate complex power at both terminals. In [25], data of phasors or symmetrical component of current ratio of both terminals has been used. Alpha Plane is applied to this ratio based on the defined different fault conditions.

A TLDP method has been presented based on wavelet transform and applied to the mathematical tools for pattern recognition, feature extraction and classification of the fault type which occurs on the transmission line [26, 27].

The fault and inrush current are detected using wavelet coefficient energy of the phase current and negative sequence current in [28]. The advantage of this method is that it is fast in detection. The disadvantage of that is that, it is sensitive to the fault resistance, fault inception angle and special noises.

The differential protection is enhanced in [29], with a classical and robust detection method. The approach however, is unable to detect interterm fault at inception level.
An empirical Fourier transform is used for transformer differential protection to improve the discrete Fourier transform accuracy on different conditions such as internal fault, inrush, and current-transformer (CT) saturation in [30].

In this paper, a new method is proposed for distinguishing the inrush current from the internal fault current of the power transformer. This method is based on the instantaneous behavior of the current. The proposed scheme is based on calculating the $\mathrm{dq} 0$ transformation of current signals in the abc phases of transformer terminals for different inrush current and internal fault signals. The approach is that new waveforms are generated by mathematical processing, and the signals are identifiable by their characteristics. A classification pattern for the discrimination algorithm is developed which results in an accurate diagnosis. To validate the proposed methodology, different states of inrush and fault currents are simulated in PSCADTM/EMTDCTM. The discrimination procedure needs only current signal data of less than a quarter of power frequency cycle and uses very simple classification rules. Eventually, both simulation and experimental results show that the accuracy of proposed method is high.

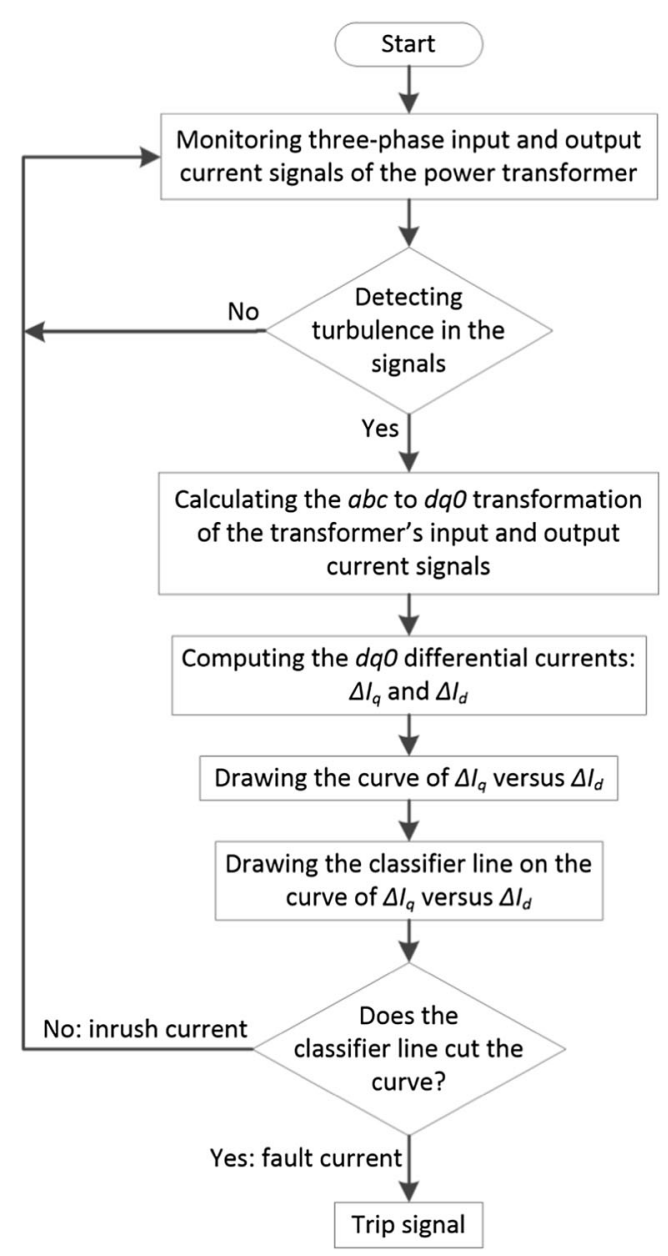

Fig. 1 Flowchart of the proposed method 


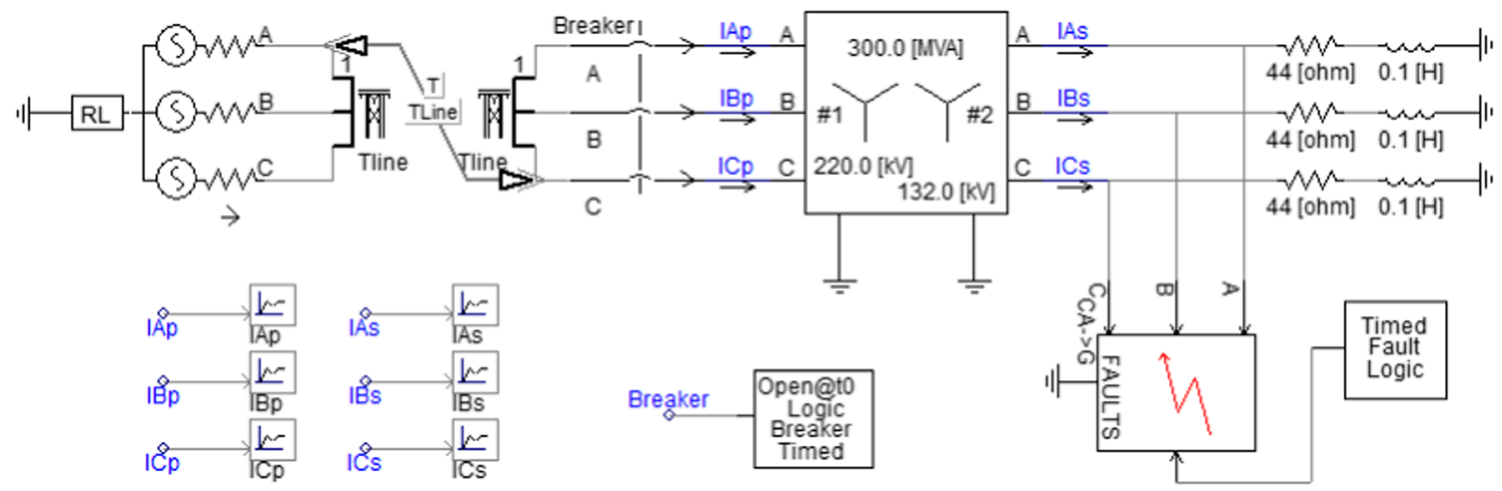

Fig. 2 Diagram of the simulated power system

The next section provides an explanation of the proposed method as well as use of Park's vector parameters, extracting the classifier, and the classification. This is followed by performance evaluation which includes the case study and both theoretical and practical simulation results. Finally, the key findings and the conclusions of the study are presented.

\section{Proposed Method}

The proposed technique for distinction between inrush currents and internal faults in power transformer differential protection is discussed in this section. The $a b c$ to $d q o$ transformation and the utilization of Park's vector components are considered that followed by the extraction of the classifiers. Finally, the proposed algorithm is presented.

\section{Park's Vector Parameters}

The $a b c$ to $d q 0$ transformation of the current signals are applied to simplify the analysis of the system as follows [31]:

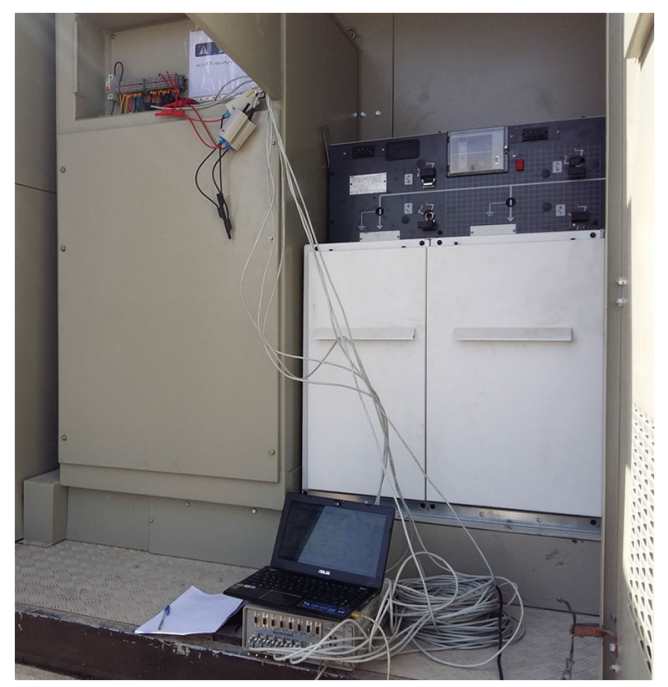

Fig. 3 Current measurement system of the experimental test
$I_{d}=2 / 3\left[I_{a} \sin (\omega t)+I_{b} \sin (\omega t-2 \pi / 3)+I_{c} \sin (\omega t+2 \pi / 3)\right]$

$I_{q}=2 / 3\left[I_{a} \cos (\omega t)+I_{b} \cos (\omega t-2 \pi / 3)+I_{c} \cos (\omega t+2 \pi / 3)\right]$

$I_{0}=1 / 3\left[I_{a}+I_{b}+I_{c}\right]$

where $\omega=2 \pi f$ and $f=50 \mathrm{~Hz}$.

Since the $a b c$ to $d q 0$ transformation is applied on both primary and secondary terminals of the power transformer, six new parameters are acquired from the base currents:

$\left(I_{a p}, I_{b p}, I_{c p}, I_{a s}, I_{b s}, I_{c s}\right) \rightarrow\left(I_{d p}, I_{q p}, I_{0 p}, I_{d s}, I_{q s}, I_{0 s}\right)$

where:

- Iap is current signal of phase a of the transformer primary winding,

- Ibp is current signal of phase $b$ of the transformer primary winding,

- Icp is current signal of phase $\mathrm{c}$ of the transformer primary winding,

- Ias is current signal of phase a of the transformer secondary winding,

- Ibs is current signal of phase $b$ of the transformer secondary winding,

- Ics is current signal of phase $\mathrm{c}$ of the transformer secondary winding,

- Idp is direct component of the transformer primary winding,

- Iqp is quadrature component of the transformer primary winding,

- I0p is zero component of the transformer primary winding,

- Ids is direct component of the transformer secondary winding,

- Iqs is quadrature component of the transformer secondary winding,

- I0s is zero component of the transformer secondary winding.

After computing the mentioned transformations, the $d q 0$ differential currents of the transformer are defined as: 
Fig. 4 Simulation results in noloaded state, in case of singlephase-to-ground fault $(A \rightarrow$

$$
\begin{aligned}
& \Delta I d=\left(I d_{p}-I d_{s}\right) \\
& \Delta I q=\left(I q_{p}-I q_{s}\right) \\
& \Delta I 0=\left(I 0_{p}-I 0_{s}\right)
\end{aligned}
$$

Here, there are several curves that could be obtained from eqs. (5), (6), and (7):

Fig. 5 Simulation results in noload state, in case of two-phase fault $(B C)$ occurrence when the switching angle is 0 , during one cycle $(20 \mathrm{~ms})$ (a) $R_{\text {fault }}=0.01 \Omega$

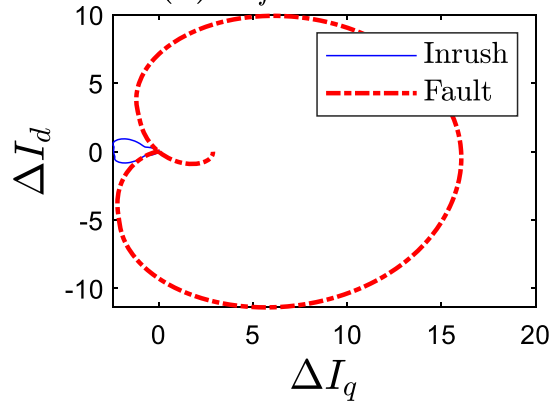

(b) $R_{\text {fault }}=20 \Omega$

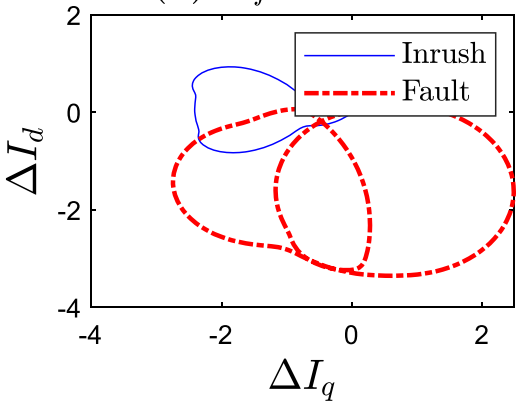

(c) $R_{\text {fault }}=50 \Omega$

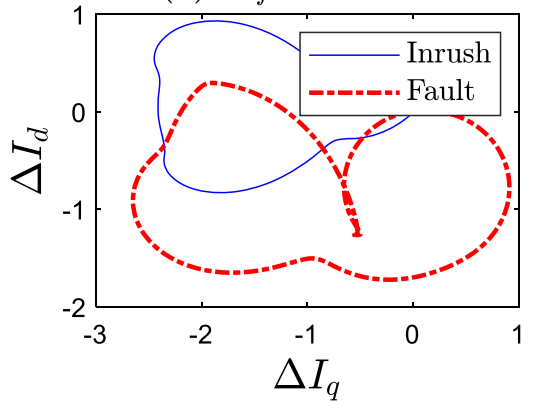

(d) $R_{\text {fault }}=100 \Omega$

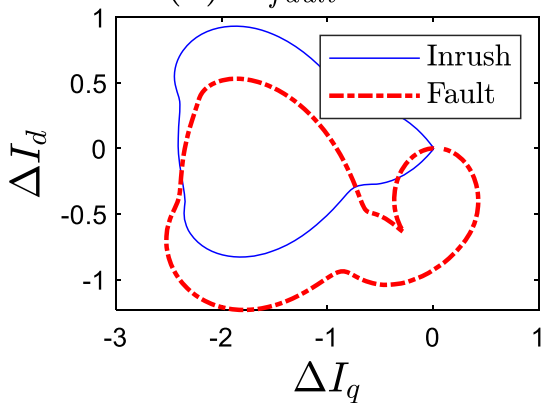

$f\left(\Delta I_{d}, \Delta I_{0}\right), f\left(\Delta I_{q}, \Delta I_{d}\right), f\left(\Delta I_{0}, \Delta I q\right), f\left(\left|\Delta I_{d}\right|,\left|\Delta I_{0}\right|\right)$,

$f\left(\left|\Delta I_{q}\right|,\left|\Delta I_{d}\right|\right), f(|\Delta I 0|,|\Delta I q|)$

All the six curves in Eq. (8) have been plotted as 2D curves for different cases of fault and inrush current signals in one cycle of the power system frequency (which equals to $20 \mathrm{~ms}$,

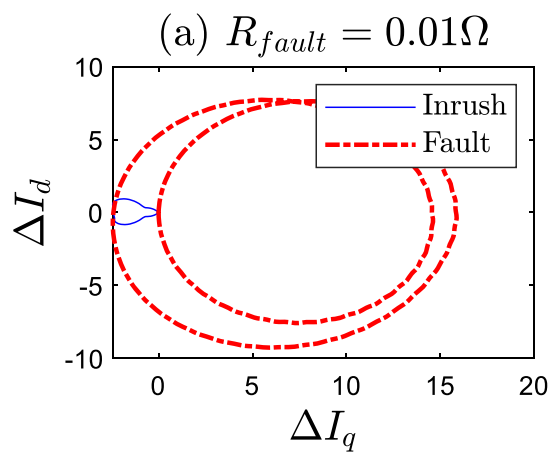

(c) $R_{\text {fault }}=50 \Omega$

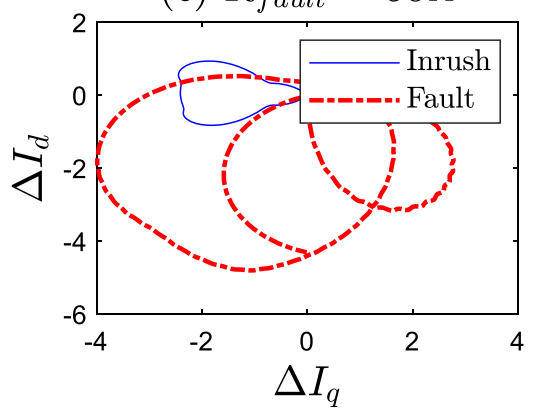

(b) $R_{\text {fault }}=20 \Omega$

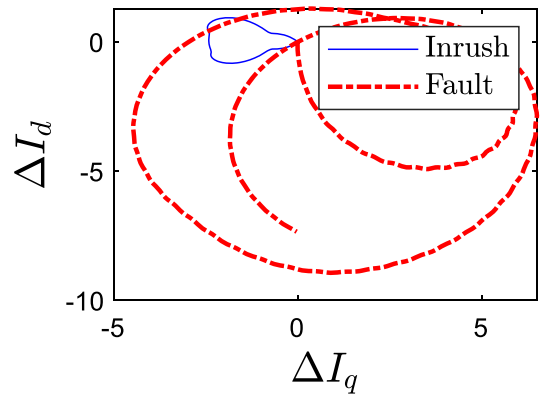

(d) $R_{\text {fault }}=100 \Omega$

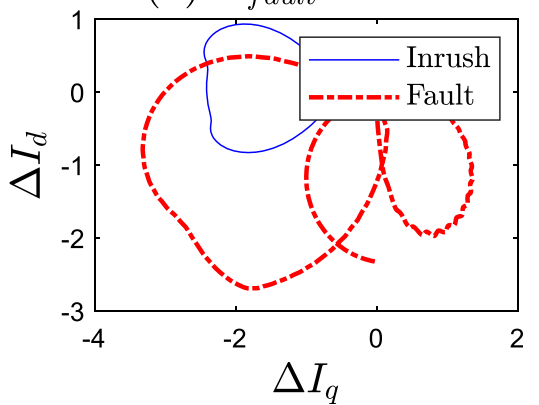


Fig. 6 Simulation results in noload state, in case of three-phase fault $(A B C \rightarrow G)$ occurrence when the switching angle is 0 , during one cycle $(20 \mathrm{~ms})$ (a) $R_{\text {fault }}=0.01 \Omega$

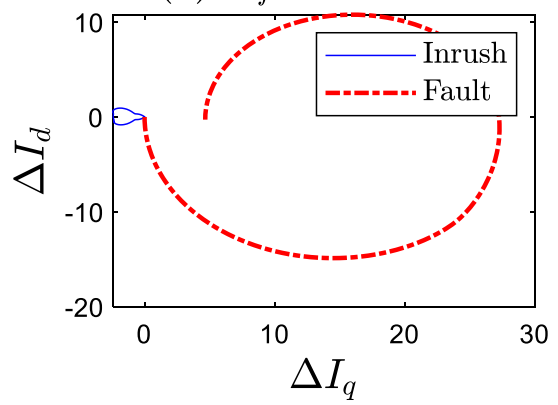

(c) $R_{\text {fault }}=50 \Omega$

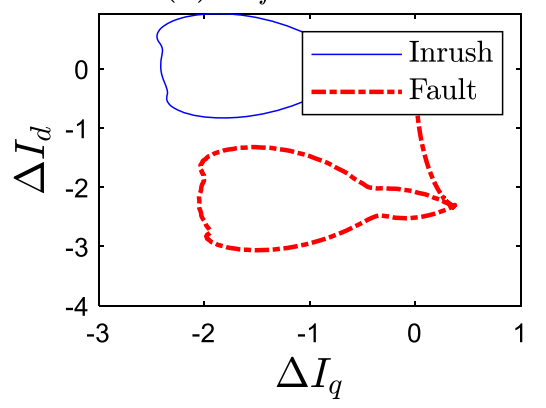

(b) $R_{\text {fault }}=20 \Omega$

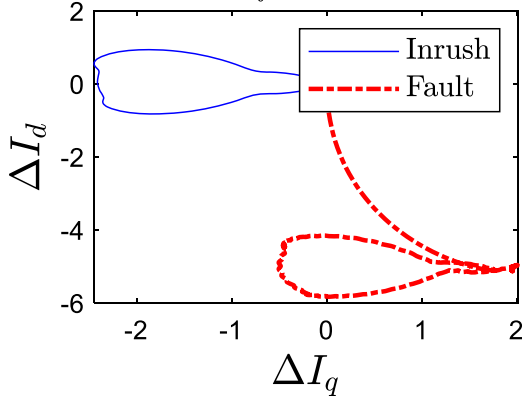

(d) $R_{\text {fault }}=100 \Omega$

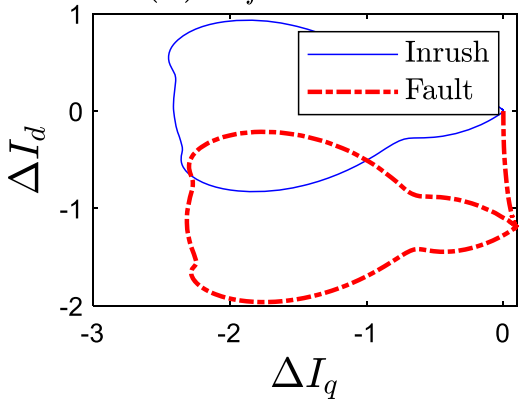

for a $50 \mathrm{~Hz}$ power system). In nearly all the plots, inrush current was recognizable from the fault. Hence, to reduce the calculations just $f(\Delta I q, \Delta I d)$ was selected as the optimum discriminative curve.

(a) Inception Angle: 0

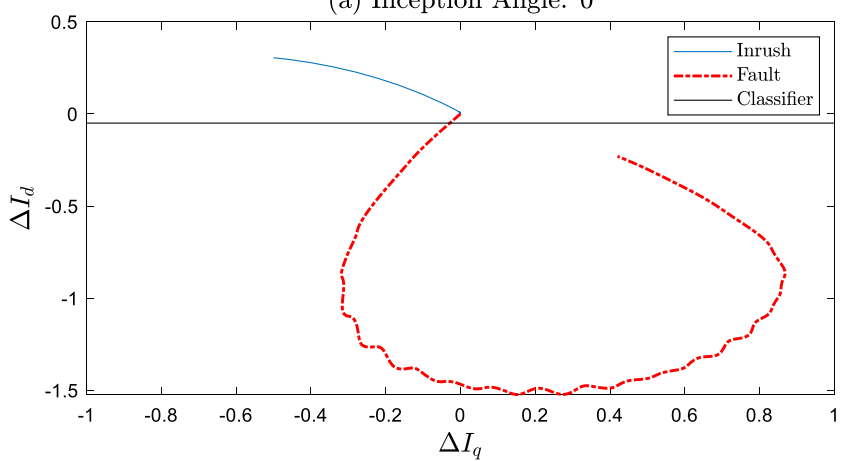

(c) Inception Angle: $\pi / 2$

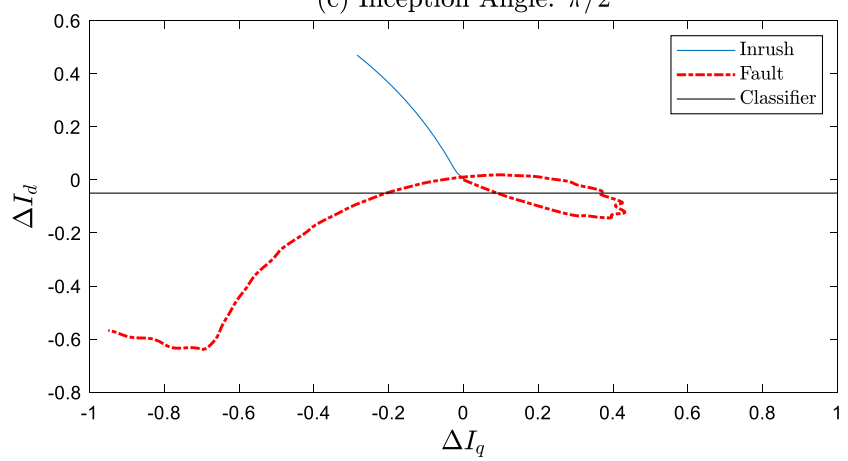

\section{Extracting the Classifier}

As it is mentioned in the previous section, the curve of $\Delta \mathrm{Iq}$ versus $\Delta \mathrm{Id}$ is selected. The characteristics of this

(b) Inception Angle: $\pi / 4$

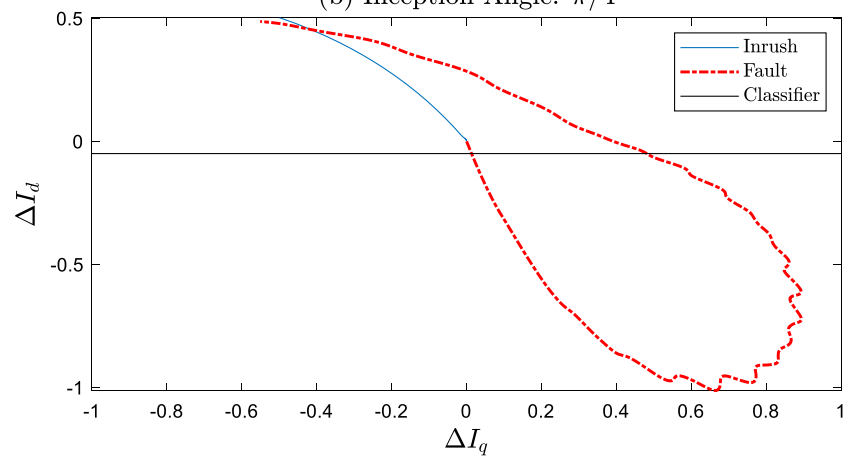

(d) Inception Angle: $3 \pi / 4$

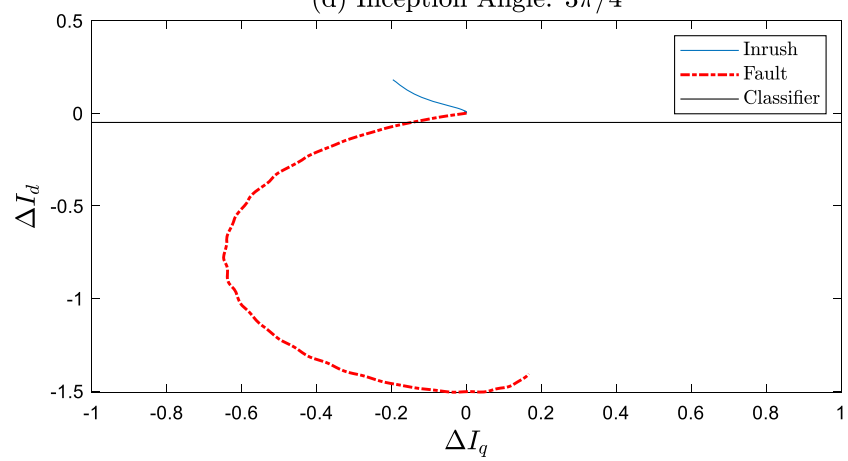

Fig. 7 Simulation results in no-load state, in case of single-phase-to-ground fault $(B \rightarrow G)$ occurrence during quarter of cycle $(5 \mathrm{~ms})$ when $R f$ ault $=50 \Omega$ 
(a) Inception Angle: 0

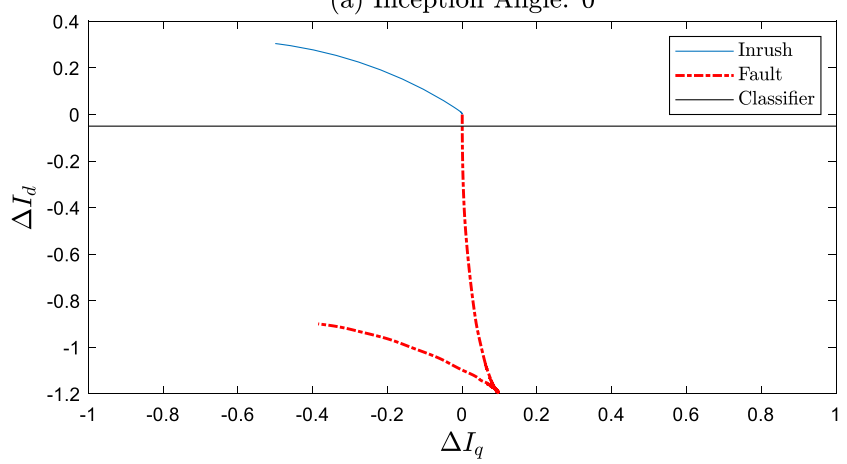

(c) Inception Angle: $\pi / 2$

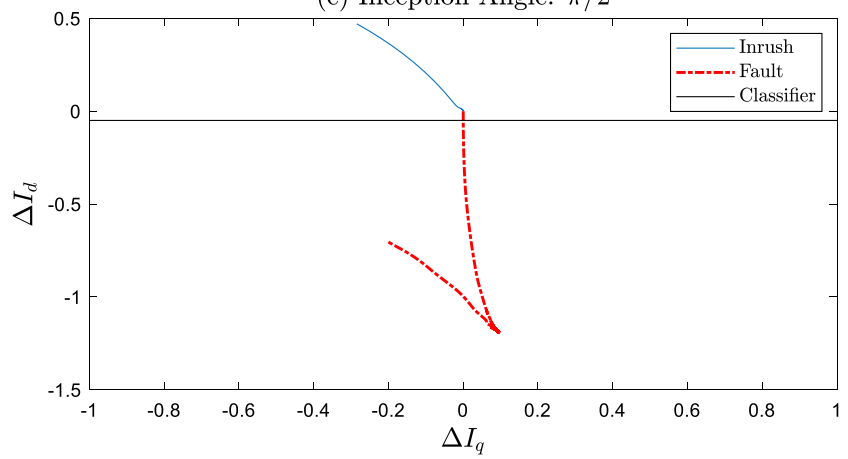

(b) Inception Angle: $\pi / 4$

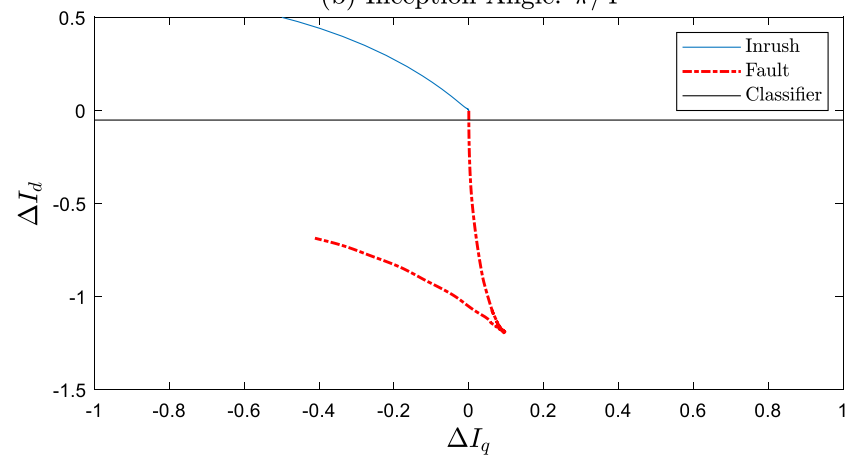

(d) Inception Angle: $3 \pi / 4$

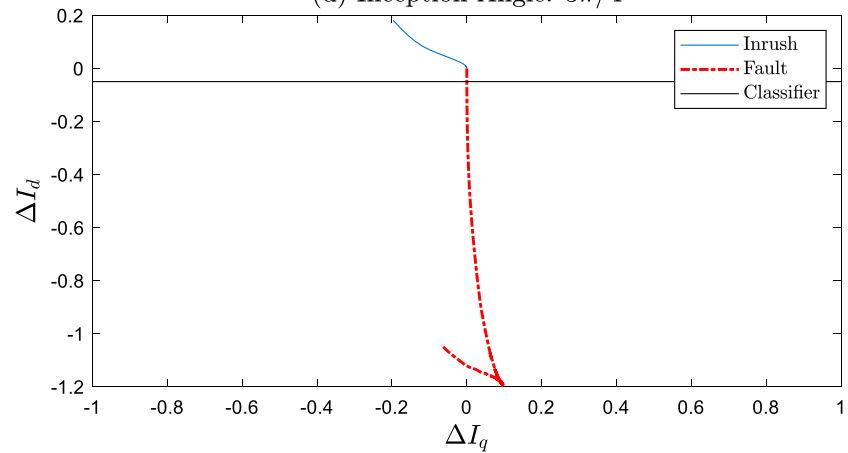

Fig. 8 Simulation results in no-load state, in case of three-phase-to-ground fault $(A B C \rightarrow$

curve is considered for the classification process. By drawing a single horizontal line on $\Delta \mathrm{Iq}$ versus $\Delta \mathrm{Id}$ curve, the line is selected as a classifier and it is saved in the

(a) Inception Angle: 0

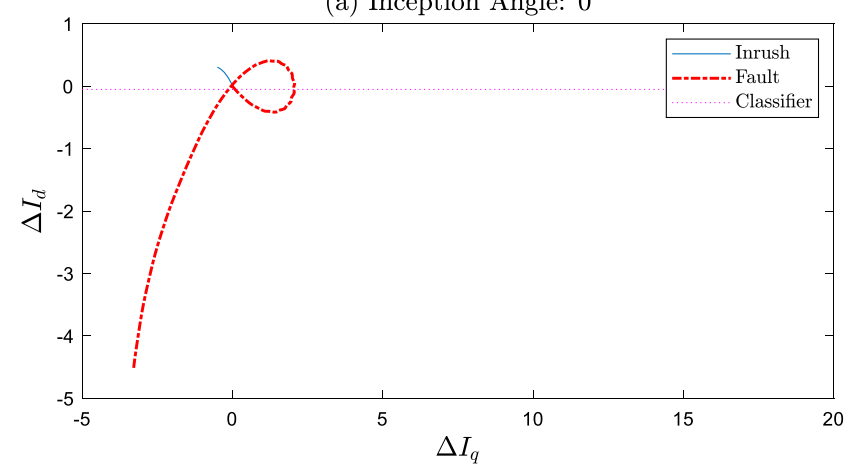

(c) Inception Angle: $\pi / 2$

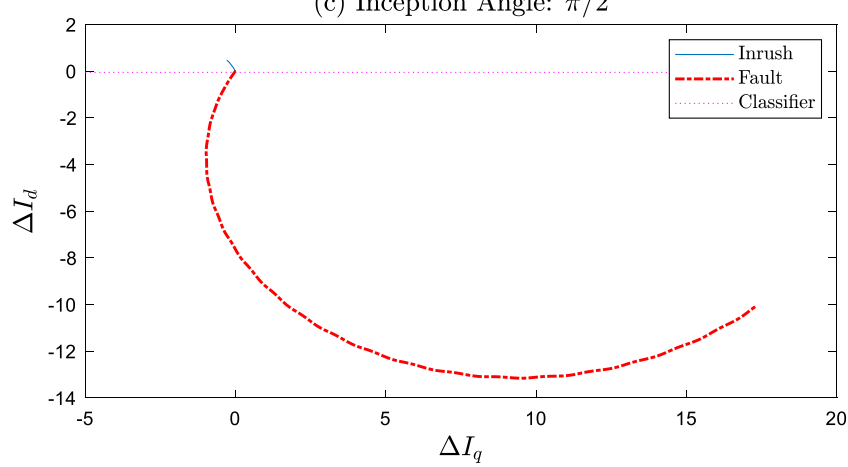

database. It is important to note that for changes in transformer tap changer, the classifier line might need to be re-extracted (Fig. 1).

(b) Inception Angle: $\pi / 4$

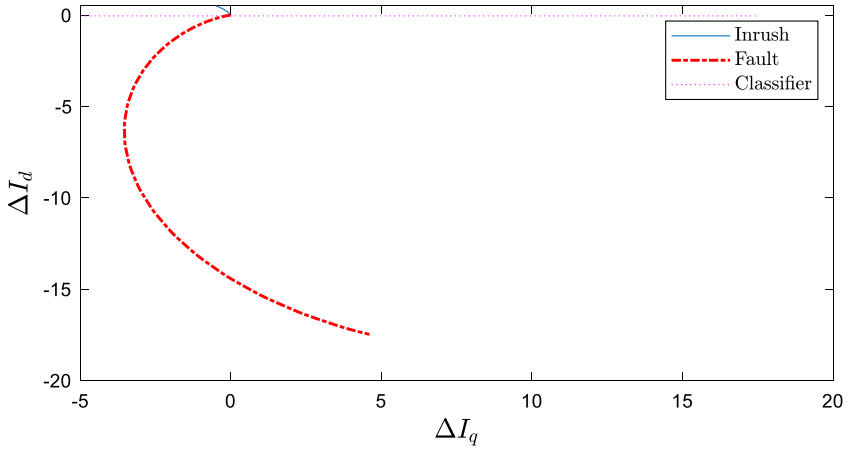

(d) Inception Angle: $3 \pi / 4$

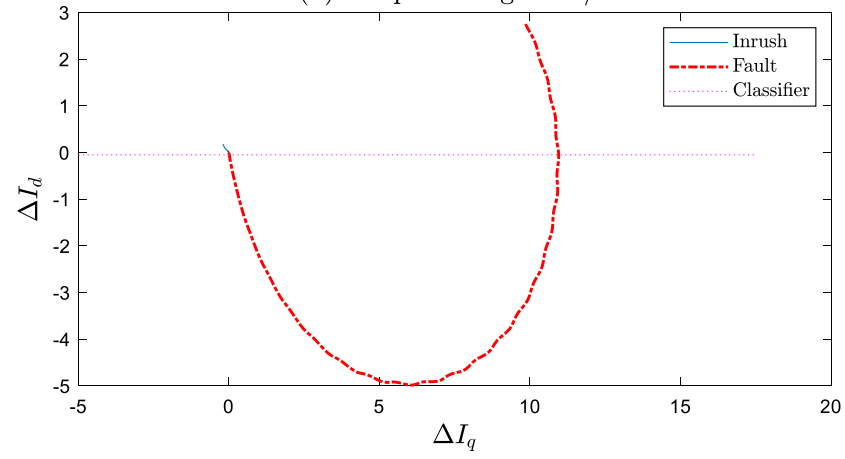

Fig. 9 Simulation results in no-load state, in case of two-phase (CA) occurrence during quarter of cycle (5 ms) when $R f$ ault $=0.01 \Omega$ 
(a) Inception Angle: 0

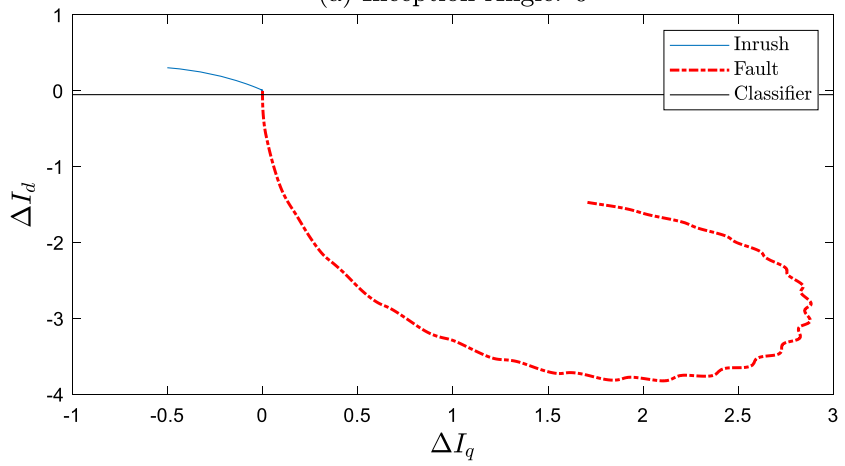

(c) Inception Angle: $\pi / 2$

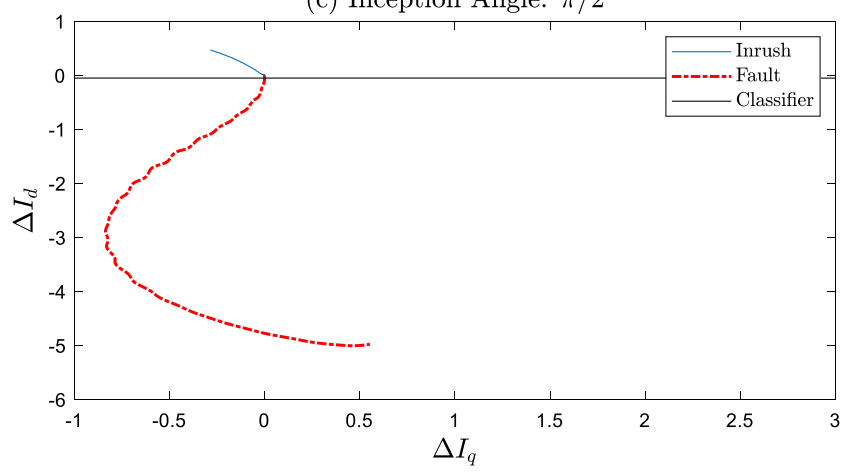

(b) Inception Angle: $\pi / 4$

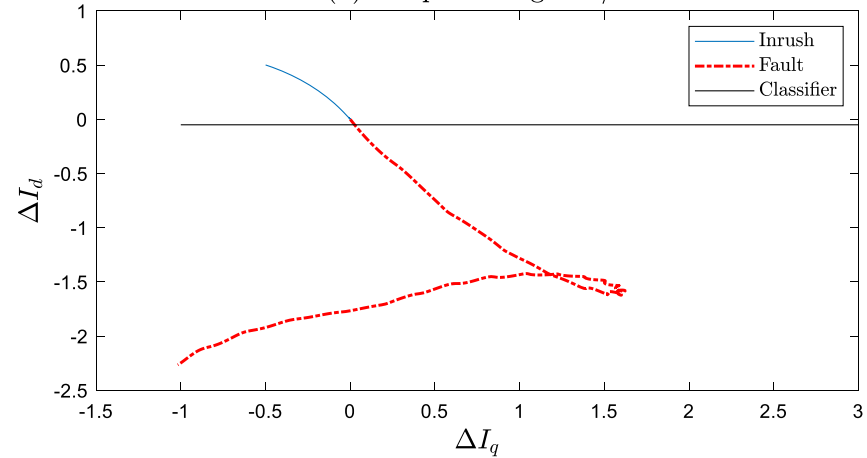

(d) Inception Angle: $3 \pi / 4$

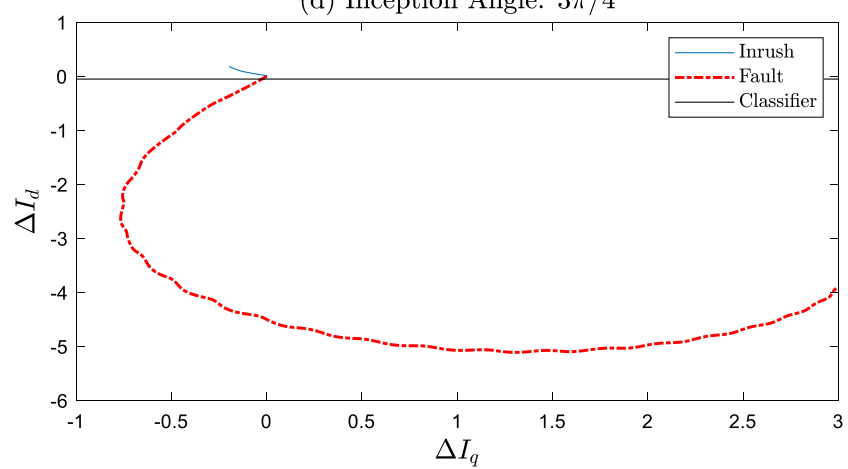

Fig. 10 Simulation results in no-load state, in case of two-phase-to-ground fault $(B C \rightarrow G)$ occurrence during quarter of cycle $(5 \mathrm{~ms})$ when $R f$ ault $=20 \Omega$

\section{Performance Evaluation}

\section{Case Study}

The system studied is a simplified three-phase model with one transformer $(220 / 132 \mathrm{kV}, 300 \mathrm{MVA}, \mathrm{YY}, 50 \mathrm{~Hz})$, which neutral connection of both sides are grounded. The transformer is connected to a three-phase generator $(220 \mathrm{kV}, 100$ MVA, $50 \mathrm{~Hz}$ ) via a $20 \mathrm{~km}$ T-Line. The power system under study is simulated utilizing PSCADTM/EMTDCTM. The diagram of system is shown in Fig. 2. The practical system under study is a real three-phase distribution transformer $(800 \mathrm{kVA}, 11 \mathrm{kV} /$ $400 \mathrm{~V}, \mathrm{YnD} 5)$. The current measurement system of the experimental test is shown in Fig. 3. Similar to the simulated
Fig. 11 The recorded inrush current of the practical test
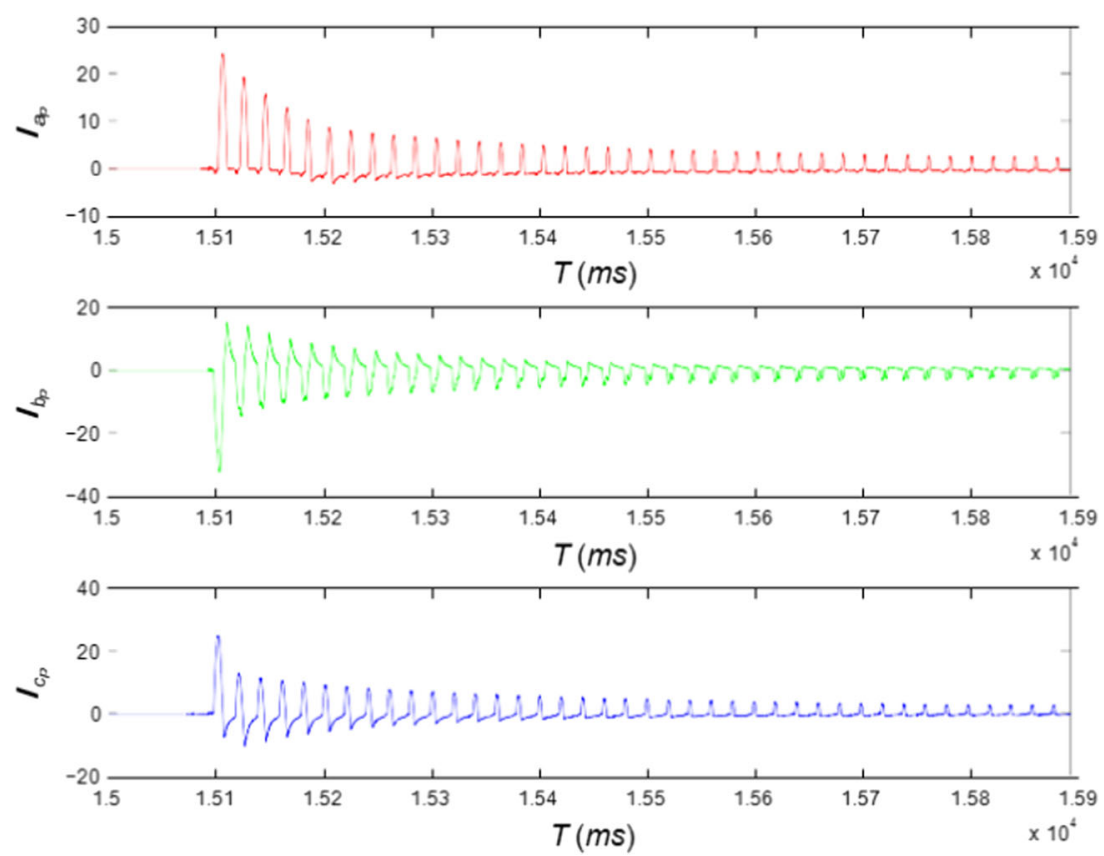
system, the output data of the practical test has also been computed via MATLAB.

\section{Simulation Results}

This section provides the theoretical results of the proposed method as well as the experimental results. In the first place, the effectiveness of the presented technique is evaluated for different types of simulated fault and inrush current signals in no-load state. Finally, the practical results of the method are presented.

\section{Theoretical Results}

As it is stated before, the system is simulated in PSCADTM/ EMTDCTM; the data is generated repeatedly for different types of faults, fault resistances $(0.01 \Omega, 20 \Omega, 50 \Omega$, $100 \Omega$ ), switching angles $(0, \pi / 4, \pi / 2,3 \pi / 4, \pi, 5 \pi / 4,3 \pi / 2$, $7 \pi / 4)$, and so on. All the output data are executed in MATLAB.

The focus of this study is on no-load mode. The experimental reason for focusing on unloaded state is that in general, a power transformer is energized when it is not connected to any loads. Then after receiving an assurance about the reliability of the power transformer and other system equipment, the second switching is performed.

The simulation results are displayed in Figs. 4, 5, 6, 7, 8, 9 and 10 for different states of fault and magnetizing inrush. The Figs. 4, 5 and 6 represent simulation results during one cycle of the power system frequency $(20 \mathrm{~ms})$, and for better comparison, each figure contains four different fault resistance values. In cases of faults with bigger resistances, the fault curves are more similar to inrush curves. The reason for this shape similarity is the presence of magnetizing inrush in the faults, which is an important factor and has been considered in the simulations. In all the figures, the fault signal contain inrush current too; because the fault is present in the switching moment, the presence of inrush in the fault signal is inevitable.

Now that the general characteristics of the $\Delta \mathrm{Iq}$ versus $\Delta \mathrm{Id}$ curve are explained, the classification of inrush and fault is being proposed in Figs. 7, 8, 9 and 10 in a quarter of power frequency cycle. The horizontal line in the aforementioned figures is the classifier. Due to the different movement direction of inrush and fault curve, a single line is used as a classifier and shows that the signals are properly identifiable from each other in less than $1 \mathrm{~ms}$ in the different states mentioned before.

$\mathrm{G}$ occurrence when the switching angle is 0 , during one cycle (20 ms).

G) occurrence during quarter of cycle (5 ms) when $R$ fault = $100 \Omega$.

\section{Practical Results}

Since the experimental test has been made on a real distribution transformer, applying different switching inception angles and short circuit faults were not feasible. Hence, just the inrush current of the transformer energization in no- load state is available. The recorded inrush current of the experiment is shown in Fig. 11. Now that the transformer currents of the energization moment are available, the discriminative curve
Fig. 12 Practical result in no-load state during quarter of cycle

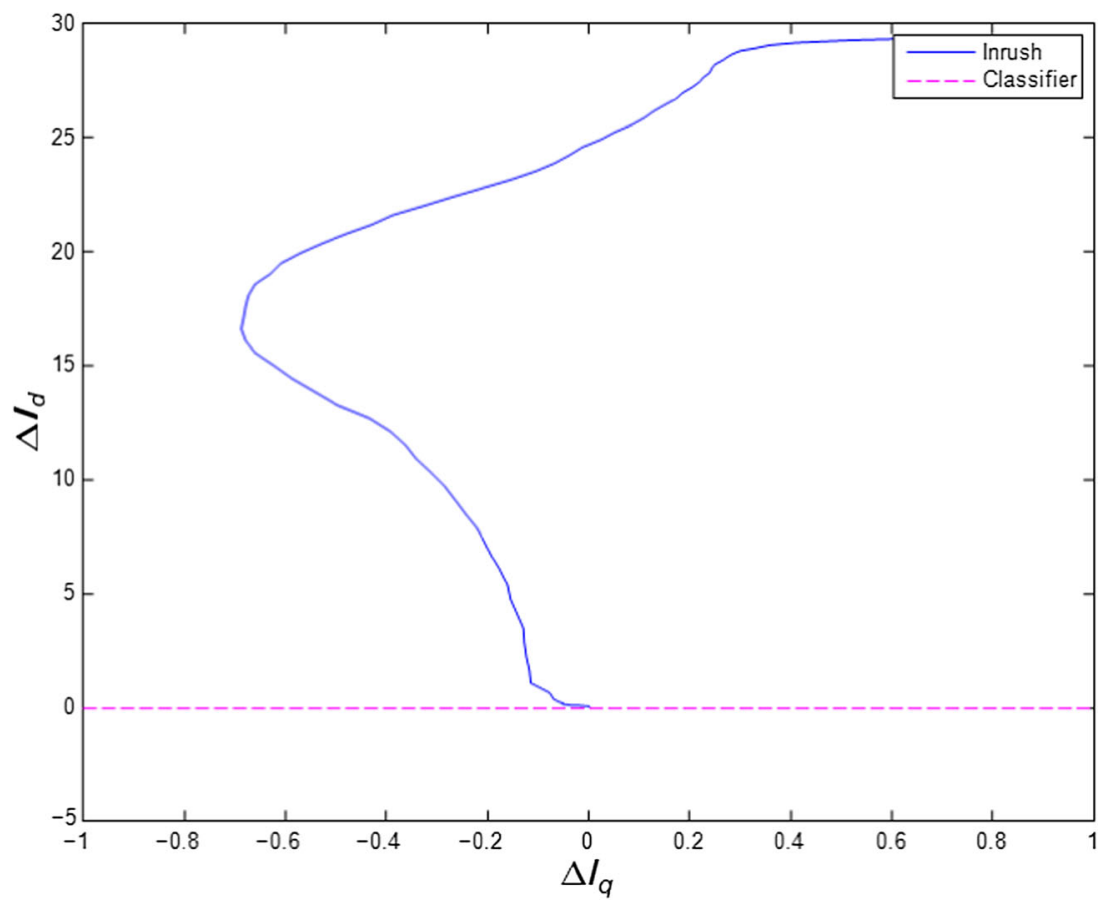


of the practical data is created. The result is shown in Fig. 12. As expected, the inrush current curve is above the classifier line and the practical experiment shows a good result.

\section{Conclusions}

In this paper a new and simple method for making the distinction between inrush currents and internal faults in power transformer differential protection using the abc to dq 0 transformation and classification curve is proposed. As it is stated, performance of the presented algorithm has been verified by simulating various cases of faults, fault resistances, different switching angles, etc. The existence of magnetizing inrush in fault signals has been considered in simulation models, which is an important factor. The study was simulated and tested in a wide variety of states, such as possible singlephase-to-ground, two-phase, two-phase-to-ground, threephase, and three-phase-to-ground faults. Interestingly, in cases of fault resistance with the value of $100 \Omega$-which is a rare condition and the shape of inrush and fault curve have similarities - the discrimination is accurate. More than 500 various cases of fault and inrush current are simulated and processed.

The proposed technique proved that due to the different movement directions of the fault and magnetizing inrush curve, the signals are properly and easily identifiable from each other in less than a twentieth of the power frequency cycle.

\section{References}

1. Hosseini $\mathrm{H}$ et al (2012) Hybrid energy production system with PV Array and wind turbine and pitch angle optimal control by genetic algorithm. Journal of World's Electrical Engineering and Technology 1(1):1-4

2. Tian M-W et al. (2019) New Optimal Design for a Hybrid Solar Chimney, Solid Oxide Electrolysis and Fuel Cell based on Improved Deer hunting optimization algorithm. J Clean Prod: 119414

3. Hosseini H, Farsadi M, Lak A, Ghahramani H, Razmjooy N (2012) A novel method using imperialist competitive algorithm (ICA) for controlling pitch angle in hybrid wind and PV array energy production system. International Journal on Technical and Physical Problems of Engineering (IJTPE) 11:145-152

4. Khalilpour M, Valipour K, Shayeghi H, Razmjooy N (2013) Designing a robust and adaptive PID controller for gas turbine connected to the generator. Res J Appl Sci Eng Technol 5(5): $1544-1551$

5. Lin X, Ma J, Tian Q, Weng H (2015) Electromagnetic transient analysis and novel protective relaying techniques for power transformer, Wiley-IEEE Press. doi:https://doi.org/10.1002/ 9781118653838

6. Hamilton R (2013) Analysis of transformer inrush current and comparison of harmonic restraint methods in transformer protection.
IEEE Trans Ind Appl 49:1890-1899. https://doi.org/10.1109/TIA. 2013.2257155

7. IEEE Guide for Protecting Power Transformers, IEEE Standard C37.91TM (2008) 8. doi:https://doi.org/10.1109/IEEESTD.2008. 4534870

8. Winders JJ (2002) Power transformers: principles and applications, Marcel Dekker, Inc.

9. Ziegler G (2012) Numerical differential protection: principles and applications, Publicis Publishing

10. Harlow JH (2012) The electric power engineering handbook: electric power transformer engineering, CRC Press

11. Perez SGA (2006) Modeling relays for power system protection studies

12. Rasoulpoor M, Banejad M (2013) A correlation based method for discrimination between inrush and short circuit currents in differential protection of power transformer using discrete wavelet transform: theory, simulation and experimental validation. Electr Power Energy Syst 51:168-177. https://doi.org/10.1016/j.ijepes.2013.02. 034

13. Hossam Eldin AA, Refaey MA (2011) A novel algorithm for discrimination between inrush current and internal faults in power transformer differential protection based on discrete wavelet transform. Electr Power Syst Res 81:19-24. https://doi.org/10.1016/j. epsr.2010.07.010

14. Mao P, Aggarwal R (2000) A wavelet transform based decision making logic method for discrimination between internal faults and inrush currents in power transformers. Electr Power Energy Syst 22:389-395. https://doi.org/10.1016/S0142-0615(00)00013-2

15. Youssef $\mathrm{O}$ (2003) A wavelet-based technique for discrimination between faults and magnetizing inrush currents in transformers. IEEE Transactions on Power Delivery 18:170-176. https://doi. org/10.1109/TPWRD.2002.803797

16. Sedighi AR, Haghifam MR (2005) Detection of inrush current in distribution transformer using wavelet transform. Electr Power Energy Syst 27:361-370. https://doi.org/10.1016/j.ijepes.2004.12. 007

17. Jazebi S, Vahidi B, Hosseinian SH, Faiz J (2009) Magnetizing inrush current identification using wavelet based Gaussian mixture models. Simu-lation Modelling Practice and Theory 17:9911010. https://doi.org/10.1016/j.simpat.2009.02.004

18. Faiz J, Lotfi-Fard S (2006) A novel wavelet-based algorithm for discrimination of internal faults from magnetizing inrush currents in power transformers. IEEE Transactions on Power Delivery 21: 19891996. https://doi.org/10.1109/TPWRD.2006.877095

19. Jazebi S, Vahidi B, Jannati M (2011) A novel application of wavelet based SVM to transient phenomena identification of power transformers. Energy Convers Manag 52:1354-1363. https://doi.org/10. 1016/j.enconman.2010.09.033

20. Alencar R, Bezerra U, Ferreira A (2014) A method to identify inrush currents in power transformers protection based on the differential current gradient. Electr Power Syst Res 111:78-84. https:// doi.org/10.1016/j.epsr.2014.02.009

21. Samantaray S, Dash P (2011) Decision tree based discrimination between inrush currents and internal faults in power transformer. Electr Power Energy Syst 33:1043-1048. https://doi.org/10.1016/j. ijepes.2011.01.021

22. Huang S, Chen H, Wu C, Guan C, Cheng C (2012) Distinguishing internal winding faults from inrush currents in power transformers using jiles- atherton model parameters based on correlation coefficient. IEEE Transactions on Power Delivery 27:548-553. https:// doi.org/10.1109/TPWRD.2011.2181543

23. Yazdani-Asrami M, Taghipour-Gorjikolaie M, Razavi M, Gholamian A (2015) A novel intelligent protection system for power transformers considering possible electrical faults, inrush current, ct saturation and over-excitation. Electr Power Energy Syst 64:1129-1140. https://doi.org/10.1016/j.ijepes.2014.08.008 
24. Almeida MLS, Silva KM (2017) Transmission lines differential protection based on an alternative incremental complex power alpha plane. IET Generation, Transmission \& Distribution 11(1):710

25. Sarangi S, Pradhan A (2017) K.:'Adaptive $\alpha$-plane line differential protection'. IET Generation, Transmission \& Distribution 11(10): 2468-2477

26. Pahade N Patii P, Badar SA (2017) Wavelet based transmission line differential protection scheme', International Conference on Power and Embedded Drive Control (ICPEDC), Chennai, India, march

27. Bejmert D, Kereit M, Rebizant W (2018) Distance protection of block transformer units. Electr Power Energy Syst 102:332-339

28. Medeiros RP, Costa FB (2018) A wavelet-based transformer differential protection with differential current transformer saturation and cross-country fault detection. IEEE Transactions on Power Delivery 33(2):789-799

29. Sevov L, Khan U, Zhang Z (2017) Enhancing power transformer differential protection to improve security and dependability. IEEE Trans Ind Appl 53(3):2642-2649

30. Murugan SK et al (2017) An empirical Fourier transform-based power transformer differential protection. IEEE Transactions on Power Delivery 32(1):209-218

31. Krause PC (1994) Analysis of electric machinery, McGraw-Hill

Publisher's Note Springer Nature remains neutral with regard to jurisdictional claims in published maps and institutional affiliations. 